\title{
The Competitive Tennis Reserve Personnel Training Drivers and Social Management in China
}

\author{
Kaiqiang Guo \\ Jiangxi Normal University \\ Nanchang, Jiangxi, China
}

\author{
Chenchu Long \\ Jiangxi Normal University \\ Nanchang, Jiangxi, China \\ guokaiqiang2008@yeah.net
}

\begin{abstract}
Competitive Tennis reserve personnel culture as a social in the form of private capital investment, it's the Competitive Tennis in development opportunities in the times and the characteristics times. this paper use the method of literature, research of Competitive Tennis reserve personnel training drivers and social management; Reserve Talents of Competitive Tennis in China socialization scale of training is developing rapidly, the Scale of competition, competition results have a certain social influence. Competitive tennis reserve personnel training in the development of society which need to drive the specific policy support and manage.
\end{abstract} culture

Keywords-Competitive tennis; reserve personnel; social

\section{QUESTIONS}

With the development of tennis occupation reform advancing our country occupation tennis, the operation of the market change rapidly changing. At the same time the State Sports General Administration pointed out that the diversification mechanism; actively encourage social do sports, school sports teams, clubs in the cultivation of sports talent reserve. To rely on social forces cultivation of reserve sports talents, encourage private schools, sports schools, secondary schools, youth sports club training sports reserve talents, and strive to create a diversified mechanism for the cultivation of sports talent reserve [1].

Therefore, the education department and the sports department must recognize the situation, timely adjustment of cultivation structure of competitive sports reserve talents, to timely according to law, project development of human resources, economic conditions by combining the diversified training model. To actively explore the Chinese tennis reserve talents of social development of modern occupation tennis training channels.

\section{THE RESEARCH OBJECT}

Part of competitive tennis reserve talents of our social culture units and individuals.

\section{RESEARCH METHODS}

\section{A. Documentary Literature; Through the Internet Network Access to the Tennis Reserve Talented Person}

Cultivation in recent ten years and the sports market operation, the mode of running school of literature, understand the current social competitive tennis reserve talents in China culture unit and individual situation and development trend, laid the theoretical foundation for the research of the full.

\section{B. Investigation Method}

Field investigation from 2007 to 2012 the national tennis competition. Investigation of the 2012 national U12 ---- 18 ranking tournament in men and women, and all participating units managers, coaches and student interviews conducted exchanges, obtained for each of the participating units to carry out the tennis movement and accurate data.

\section{Statistical Analysis Method}

Classified statistical processing of data to investigate the use of Excel statistical software.

\section{The RESUlts OF STUdy AND ANALYsis}

Social competitive tennis reserve personnel in our country is still in the development stage of the training scale, form, social folk capital to invest in tennis school and the The Racquet Club Hotel talents training mode. Such as Chaoda tennis school, The Racquet Club Hotel, The Racquet Club Hotel, Shen coal ingenuity. And in the national many non-academic training and education institutions tennis schools and clubs, tennis training site.

\section{A. Tennis School and the Racquet Club Hotel Recruitment Scale and Structure Characteristics}

With the development of market economy, the social culture of children and adolescents unit admissions for each aspect of the scope of. Scale and structure characteristics; later, small scale, stock management, single sex school structure, source of funds have more channels, market operation. In training children in addition to the high level sports clubs, sports teams, sports teams can also enter the institutions of higher learning. In order to Chaoda international tennis school as an example; it has the following several aspects of enrollment, "Star" enrollment, enrollment tennis training site [2]

\section{B. Training Cost Sharing}

Social competitive tennis reserve personnel training is mainly characterized, the implementation of compensation for the training, the cultivation of reserve talents completely and the market, operating according to market rules, only to give the country a macro policies and regulations for protection, the market mechanism play a dominant role in the camp. The training process cost, self - operation, self- 
financing, paid training, the paid transfer. So through paid training practice of juvenile athletes, not only increase the training of social investment, and mobilize the enthusiasm of the society, promote the development of competitive.

\section{Competition and Talent Way}

Through research 2008-2012 China Tennis Association held various children's tennis game related data;[3] as a social culture of competitive tennis back-up personnel have participated in the competition, competition and talent show changes way. The evolving, the emergence of a number of outstanding competitive tennis reserve personnel. See Fig. 1; Fig. 2; Fig. 3; specific characteristics;

(1)From the 2012 competitive tennis reserve personnel training of participating social distribution chart shows; the number of entries for 74 people, accounted for the proportion of the total number of entries of $10.7 \%$ [from 2007 to 2012 the National Tennis Championship, 2012 ranking tournament in tegralranking as an example. Chart 1;

(2) scores distribution in the (U12) - (U18) group and all seats, Yam ahana club in the (U12) - (U14) rankings, (U18) the individual participants have many elite, ranking. Chart 2;

(3) High level athletes of conveying to the famous university has certain social influence. Chart 3;

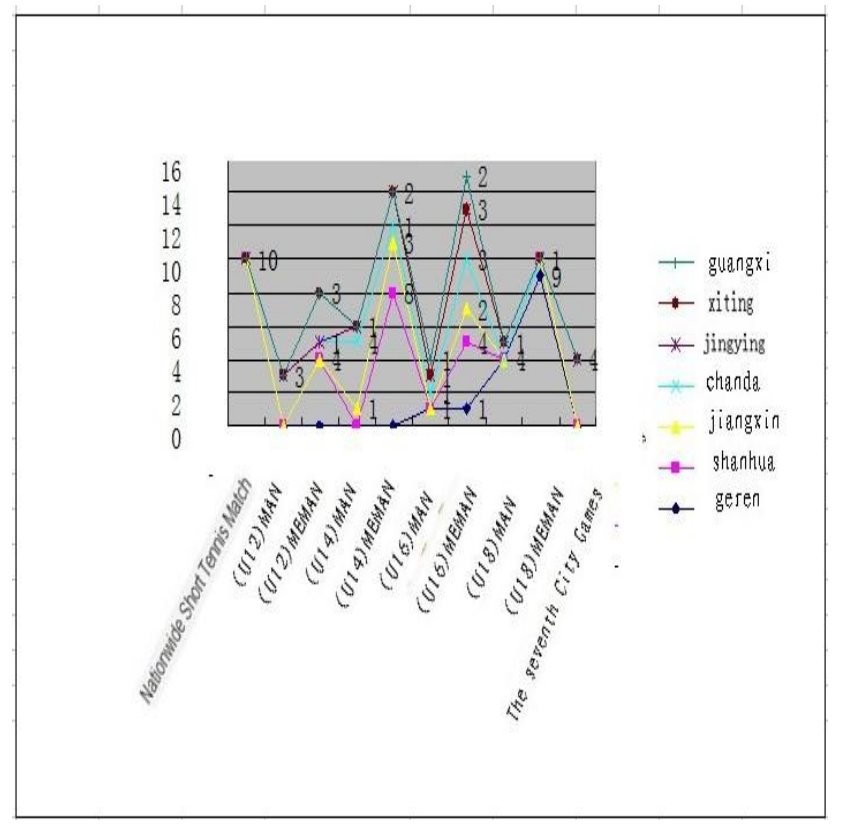

Figure 1. 2012 competitive tennis reserve personnel training the social distribution map of $n=74$

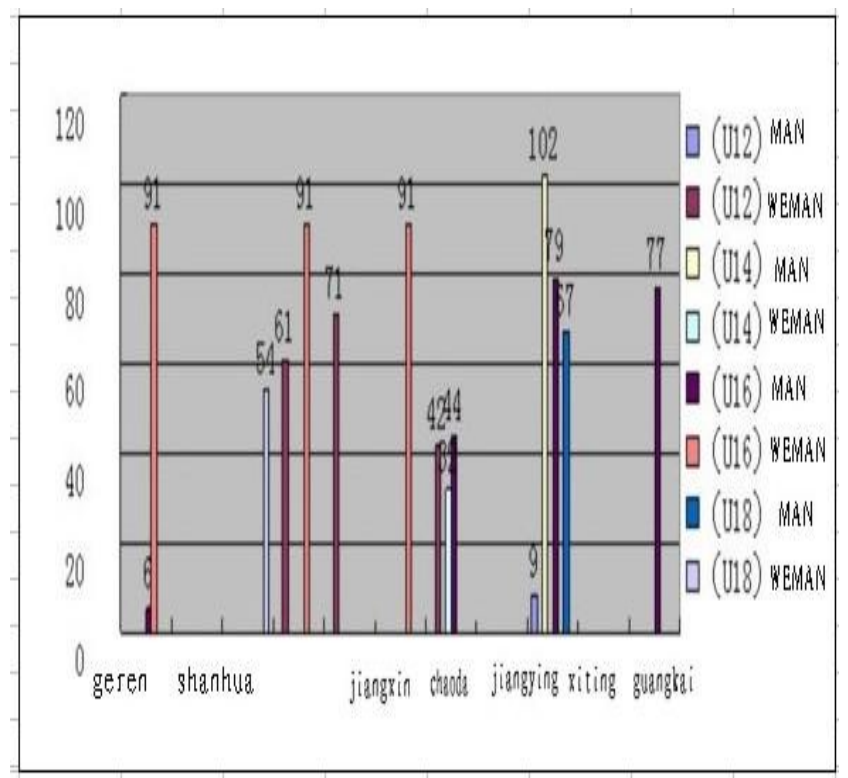

Figure 2. 2012 competitive tennis reserve personnel social schedule result distribution game culture

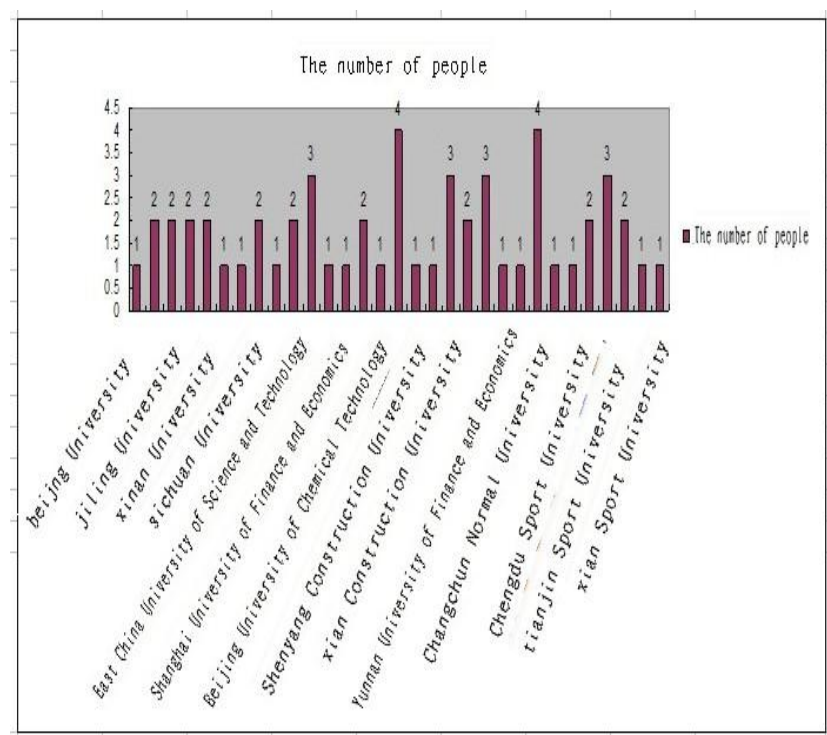

Figure 3. $n=562012$ Chaoda international transport to the famous University of high level athletes

Raw data from Chaoda international tennis school http://www.cdtennis.com/

\section{Factors}

Objectively speaking social competitive tennis reserve personnel in our country to foster the development of nearly 10 years, its development is not everything is going smoothly., With hardships and frustrations. The main control factors;

1) The obvious contradiction between learning and training; over the years, the socialization of young tennis players training, is the competitive professional training, or amateur training and cultural learning combines path, has been plagued by parents' decision, many teenagers because of cultural learning and forgo the competitive professional 
training, have great restriction to competitive tennis back-up the cultivation of talents. First it training time still with the traditional sports school, systematic training in sports law, training 5-7 times or more a week, at the same time the school was not ready education qualification, parents are difficult to accept. The sports reserve talent training should be based on education, at the same time to consider the personal development, family pursuit, have market demand, only in this way will be the sustainable development of competitive tennis career.

2) coaches need to improve the level; in sports training, the trainer own quality and ability, directly affects the work quality of the training and sports reserve talent. In recent years, from the social training institutions survey found that they have the following characteristics.

(1)The State Sports General Administration through various coaches post training and learning, education level of socialization do tennis school coaches have been greatly improved.

(2)The State Sports General Administration has issued the "Interim Measures for coaches management" and a series of regulatory documents, the coaches of the management work has played a certain role, but in some tennis training machine. The situation there is still a gap.

(3) There are a few social training institutions degree is high and low ability of coaches, or their own quality is low, do not pay attention to professional ability, and lack of international exchange, in addition, qualifications, coaches, coaches treatment, promotion incentive mechanism, also affect the training part of the positive and competitive tennis reserve personnel.

3) Economic interests Duanpingkuai affects development planning; lack of constant heart of career management, but flower briefly as the broad-leaved epiphyll um . Often the equity transfer, the school, the name of the club to the phenomenon of frequent, also taught at various tennis school, club coaches, dominate some by economic benefit drive, presents the temporary employment concepts and management, no dedication and long service plan, lack of business enterprise. Emergence of defects in the management and strategic development planning failure. This situation not only restricts the social forces to run schools, improve the quality of tennis club, but also related to the rise and fall of their. This phenomenon can be said to be the bottleneck restricting its development.

\section{V.DRIVING AND MANAGEMENT}

In March 7, 2013, the Ministry of Education (microblog ), Minister Yuan Guiren members suggested that response. What is the Chinese education dream? "Make no social distinctions in teaching, teach students in accordance with their aptitude, lifelong learning, talent, is the Chinese education dream. "" I agree with the private education into the government work report, private schools more government, more happy. "[4]

A. According to "private school regulations formulated by the State Council" policy, the basic principles on the role of schools, private schools, made specific provisions. Therefore, we should support social capital for a competitive tennis back-up talent socialized with qualification training private schools, the training aim to achieve diversification,[5] thus avoiding a three talent, to the society, family, the waste of resources caused by the vicious spiral of funds. Around the sports and education administration departments to actively support the development of competitive tennis reserve personnel training in social policy and management, should be. Starting from the actual situation of the relevant functional departments, to implement the "Regulations" policy, be the same outside and inside attitude should be set up; improve and consolidate the competitive tennis reserve personnel social culture environment and development.

B. Allow and promote domestic and foreign funds to carry out the tennis school Sino-foreign cooperation in running. Foreign investment company to carry out educational activities within the territory of China shall comply with the "catalogue for the guidance of foreign investment industries" (2011Amendment) regulations. Allow foreign capital through Sino-foreign cooperation in running schools outside the Party School in accordance with the "Regulations" and its implementation approach of Chinese-foreign cooperation in running [6] Encourage the private capital cooperation and tennis schools within the territory of China, to participate in the introduction of foreign high-quality educational resources, Chinese-foreign cooperatively-run schools shall organize high level. Foreign competitive tennis back-up personnel social culture has a long history, there is a set of scientific training and management experience, is worth to introduce and study.

C. The international experience and the historical experience shows that, for any country's athletic sports cannot completely rely on the government arranged, because of limited financial resources, the development of the Chinese sports, must put more resources to attract support in society, sports field. Social competitive tennis reserve personnel training unit as a private tennis school, in human resources should be the same as with public schools, should treat school. Concerned about the coach needs, a reasonable solution to the difficulties, are important factors for stable coaches. We should treat the three equality,

(1) to ensure private tennis school enjoy competitive sports schools with the public the same treatment in enrolling new students, foreign exchange.

(2) according to law to promote private tennis school coach calculation and public sports school coaches enjoy equal treatment in the evaluation of professional titles, age.

(3) In order to implement the public sports school students enjoy the same rights and public schools in the aspects of education, the national student loan, national scholarship, grant the difficulties of life, employment etc ..

D. The sports administration departments and education departments should actively guide the private tennis school, The Racquet Club Hotel feature creation, first in the policy to support. A comprehensive clean-up the discriminatory policy against them, breaking the ownership of corporate property, focus their development property problem. In the capital, major projects in the planning, put them into view, incorporated. To set up a special fund, to 
reward high school quality, a good social reputation private tennis school, The Racquet Club Hotel. Second, is to standardize the management, to strengthen the private tennis school, The Racquet Club Hotel, the work of Party building, to improve their ideological and political education work. To improve the internal governance structure, safeguard the legitimate rights and interests, and standardize its education behavior. Once again, is to promote the reform, private tennis school, The Racquet Club Hotel now exist many problems, should actively promote the pilot, formed the perfect for-profit and non-profit private tennis school, The Racquet Club Hotel classification management system and policy support, promoting the sustained, healthy development. In order to achieve complementary advantages, brand share win-win situation.

E. The sports administration departments and education departments, to develop good competitive tennis reserve personnel training management socialization development planning, the development planning is a system project, to develop a set of operational mechanism from the macroscopic, microscopic formulation of specific measures and methods to achieve this goal. Practical for them a good place, find a good coordinate, at the same time to grasp the competitive tennis running in the era of opportunities and era features of development in China, captured the spirit of the times. Formed its own unique education and development value, so as to construct their own private tennis school, The Racquet Club Hotel cultural form, build their own unique distinctive personalized forms of organization and management and competitive tennis reserve personnel training pattern.

F. Private tennis reserve talents school, The Racquet Club Hotel, should strengthen the scientific talent selection and training, only to start from the scientific material, scientific training as a pilot, to explore the competitive tennis law of youth, to seek the theory basis to solve the problem and fundamental way. Should coaches to learn the theory of competitive sports, master the scientific method, improve the quality of competitive tennis back-up personnel.

\section{CONCLUSION}

A China's competitive tennis reserve personnel training scale is currently in the socialization of new changes different development stage, has certain social influence in the scale, performance, personnel.

B The obvious contradiction between learning and training, the quality and ability level is not high; economic interests Duanpingkuai phenomenon management, strategic development planning defects and failures. Is the development of the main factors.

C Competitive tennis reserve personnel social culture is interactive and educational mechanism, broadly social competitive tennis reserve personnel training and development, the need to drive the specific policy support and interest and management.

D Specific measures; should support social capital for a competitive tennis back-up talent socialized with qualification training private schools, the training aim to achieve diversification, allow and promote domestic and foreign funds to carry out the tennis school Sino-foreign cooperation in running. Actively guide the private tennis school, The Racquet Club Hotel is the creation of the characteristics of. Social competitive tennis reserve personnel training unit as a private tennis school, in human resources should be the same as the public schools. Making a good competitive tennis reserve personnel training management socialization development planning, strengthen scientific selection and training, improve the quality of competitive tennis back-up personnel.

\section{ACKNOWLEDGMENT}

Foundation Item: Social Science Fund of Jiangxi Education Department (2011); Project Number: TY1112

\section{REFERENCES}

[1] National Sports Bureau website. Http :/ / www.sport.gov.cn/

[2] Chaoda international tennis school http://www.cd-tennis.com/

[3] 2008-2012 national tennis competition, order books, book report

[4] Xinhuanet.com, the Ministry of Education (micro-blog) minister Yuan Guiren members suggested that response. What is the Chinese education dream?

[5] Of the people's Republic of China the seven National City Games "Nanchang bank" Cup tennis final order book, book report

[6] Of the people's Republic of China "http://www.moe.gov.cn/" private school regulations 